\title{
Helicobacter pylori-induced atrophic gastritis progressing to gastric cancer exhibits sonic hedgehog loss and aberrant CDX2 expression
}

\author{
A. SHIOTANI*, H. IISHI†, N. UEDO $\dagger$, R. ISHIHARA $\dagger$, S. ISHIGURO $\dagger$, M. TATSUTA $\dagger$, Y. NAKAE \\ M. KUMAMOTO末, T. HINOI§ \& J. L. MERCHANT§
}

*Health Administration Center, Wakayama University, Wakayama, Japan; †Department of Gastrointestinal Oncology, Osaka Medical Center for Cancer and Cardiovascular Diseases, Osaka, Japan; $\$$ Department of Internal Medicine Aishinkai Nakae Hospital, Wakayama, Japan; §Department of Internal Medicine, University of Michigan, Ann Arbor, MI, USA

Correspondence to:

Dr A. Shiotani, 930 Sakaedani

Wakayama City, Wakayama

Prefecture 640-8510, Japan.

E-mail: shiotani@center.wakayamau.ac.jp

Publication data

Accepted 15 March 2006

\section{SUMMARY}

\section{Background}

The loss of sonic hedgehog is an early change that occurs in the mucosa prior to neoplastic transformation and correlates with the type of intestinal metaplasia. Aberrant expression of $\mathrm{CDX}$ has also been shown to correlate with the development of intestinal metaplasia.

\section{Aim}

To examine CDX2 expression in the non-cancerous mucosa of patients with gastric cancer and compared it to CDX2 expression in controls with intestinal metaplasia.

\section{Methods}

Sixty patients who had undergone endoscopic mucosal resection for early gastric cancer and 60 gender- and age-matched controls were studied. Two specimens each were obtained from the greater and lesser curves of the corpus and from the greater curve of the antrum. Expression of CDX2 and sonic hedgehog were evaluated by immunostaining.

\section{Results}

Gastric cancer was associated with a higher frequency of incomplete intestinal metaplasia $(\mathrm{OR}=8.3 ; 95 \% \mathrm{CI}, 3.7-18.9, \quad P<0.001)$. CDX2 negatively correlated with sonic hedgehog expression, however, multivariate analysis revealed that CDX2 correlated with the intestinal metaplasia scores. Sonic hedgehog indices were lower and CDX2 staining in the corpus lesser curve was higher in the cancer group than in the controls. Sonic hedgehog indices in the corpus decreased and CDX2 indices in both areas increased in patients in the ascending order of those without intestinal metaplasia, those with complete intestinal metaplasia and those with incomplete intestinal metaplasia $(P<0.001)$.

\section{Conclusions}

Loss of sonic hedgehog expression and aberrant expression of CDX2 correlates with the type of intestinal metaplasia and may play a role in carcinogenesis. 


\section{INTRODUCTION}

The most widely accepted notion about gastric cancer is that the majority of cases evolve through a multistep process starting with superficial gastritis, progressing to atrophy with intestinal metaplasia (IM), followed by the development of dysplasia and finally carcinoma. ${ }^{1}$

Gastric IM has been classified as complete (small intestine) or incomplete (colonic) using immunohistochemical staining techniques. Another classification categorizes IM into three types: I (complete), and II and III (incomplete). ${ }^{2}$ Type I (complete) involves sialomucins similar to those found in the mucosa of the small intestine and is the most common type. The columnar cells of type III contain sulphomucins. A large number of studies have evaluated the significance of type III IM as a risk factor for intestinal-type gastric cancer using surgical specimens of human stomach with gastric cancer. ${ }^{3-6}$ However, type III IM in biopsy samples is highly specific for cancer but has low sensitivity. ${ }^{2}$ Moreover, the detection of IM in routinely obtained endoscopic biopsy material is subject to sampling error and is not thought to be a suitable marker to detect groups at high risk for gastric cancer. ${ }^{7}$ We have previously shown that IM, especially incomplete IM, detected in endoscopic biopsy samples from the corpus lesser curve is highly specific and sensitive for gastric cancer and is therefore likely to be a histological highrisk marker for the intestinal-type gastric cancer. However, the development of IM, as well as its relationship to gastric cancer, remains unclear.

The peptide morphogen called hedgehog was initially identified during genetic screening of the fruit fly Drosophila. ${ }^{8}$ Mammalian members of the hedgehog morphogenic family such as sonic hedgehog (Shh), Indian hedgehog (Ihh) and desert hedgehog (Dhh) are essential regulators of many patterning processes throughout both vertebrate and invertebrate development. ${ }^{9}$ Shh and Ihh are co-expressed in the gut endoderm in partially overlapping patterns beginning in the early somite stages. ${ }^{10,11}$ Shh null mice exhibit gastrointestinal malformations such as incomplete separation of the trachea and oesophagus, gut malrotation, small intestinal and anal atresias, and replacement of the normal gastric epithelium with intestinal metaplastic cells. ${ }^{12,13}$ In a study conducted on humans by van den Brink et al. Shh mRNA and Shh protein were shown to be abundantly expressed in the normal gastric fundus, whereas no Shh protein was observed in the oesophagus or intestine. Ectopic Shh expression was observed in fundic gland metaplasia. ${ }^{14,15} \mathrm{We}$ have recently shown that the loss of Shh is an early change that occurs in the mucosa prior to neoplastic transformation and correlates with the type of IM. ${ }^{16}$

The CDX proteins are intestine-specific transcription factors encoded by human $c d x 1$ and $c d x 2$ genes. ${ }^{17}$ These genes constitute the mammalian homologues of the Drosophilia homeobox gene, caudal, which is required for anterior-posterior regional identity. ${ }^{18,} 19$ In adult mammals, the expression of these genes is restricted to the epithelium of the gut from the duodenum to the large intestine, where they act as master regulators for intestinal development and differentiation. ${ }^{17}$ In particular, loss of CDX2 expression leads to focal gastric differentiation in the colon, ${ }^{20}$ while aberrant expression of CDX2 in the upper gastrointestinal tract is a key event in the pathogenesis of Barrett's mucosa in the oesophagus and of IM in the stomach. ${ }^{21,22}$ CDX2 is also expressed in adenocarcinomas from various organs such as the stomach, colon, pancreas, gall bladder and lung, and may be clinically useful in better predicting outcome in patients with advanced cancer. ${ }^{23-27}$

Loss of Shh and aberrant expression of CDX2 correlate with the development of IM. This suggests that the ability to predict neoplastic transformation may be enhanced when both Shh and CDX2 expression are taken into consideration. A study of both CDX2 and Shh expression in the background mucosa of patients with gastric cancer might help to clarify our understanding of how IM develops and its relationship to gastric cancer, but no such study has been performed. Here, therefore, we compared Shh and CDX2 expression in control subjects with expression in the non-cancerous mucosa of patients with early intestinal-type gastric cancer using fixed-point biopsy samples. We also assessed the relationship between the expression of these two proteins and the scores for gastritis related to Helicobacter pylori infection.

\section{METHODS}

This was a case-control study of patients with a history of endoscopic mucosal resection (EMR) for early gastric cancer. The study was performed at the Osaka Medical Center for Cancer and Cardiovascular Diseases and Aishinkai Nakae Hospital in Japan. Patients were enrolled for the study between November 2003 and January 2005. 


\section{Patients}

Patients with a medical history of EMR for early stage, non-cardia intestinal-type gastric cancer without lymph node metastasis were evaluated on the basis of age, gender and the presence of $H$. pylori infection. Subjects who underwent endoscopy for follow-up to peptic ulcer or health screening formed the non-cancer control group. Patients were excluded if they had undergone $H$. pylori eradication, used antisecretory or non-steroidal anti-inflammatory drugs, or had haemorrhagic diseases, insulin-dependent diabetes mellitus cirrhosis or renal failure. Demographic data collected at study entry included age, gender, smoking habit, alcohol consumption and drug treatments. Drinking and smoking were defined as 'regular' when consumption was more than $35 \mathrm{~g}$ for ethanol or five cigarettes per day respectively. The study was approved by the Osaka Medical Center for Cancer and Cardiovascular Diseases Ethical Committee, and written informed consent was obtained from each patient.

\section{Histopathological grading}

Endoscopies were performed by experienced endoscopists after patients had fasted for $12 \mathrm{~h}$. Two specimens from each sample site, the greater curve of the antrum and greater and lesser curves of the corpus, were stained with haematoxylin and eosin, then additionally with Giemsa stain to score $H$. pylori density. A Visual Analogue Scale ranging from 0 (absent/normal) to 3 (maximal intensity) was used to score the following four parameters: inflammation (inflammatory cell infiltration), glandular atrophy, IM and $H$. pylori density according to the updated Sydney classification. ${ }^{28}$ Well-oriented tissue sections with gastric pits and glands cut longitudinally and visible along the entire isthmus zone were selected for quantitative analysis.

\section{Subtyping IM}

Samples were also stained with Alcian blue (AB)/high iron diamine (HID) to categorize IM as the complete type (type I) or incomplete type (types II and III). Slides were immersed in HID solution for $20 \mathrm{~h}$ at room temperature, then rinsed with deionized water and stained with $1 \% \mathrm{AB}(\mathrm{pH} 2.5)$ for 2 min. IM subtyping was done according to the system of Filipe et $a .^{2}$

\section{Diagnosis of $H$. pylori}

Venous blood samples were analysed for specific IgG H. pylori antibodies with an enzyme-linked immunosorbent assay (ELISA) kit using the E plate test (Eiken Kagaku, Inc., Tokyo, Japan). Patients were considered to be infected with $H$. pylori if the serum test was positive or if evidence of chronic gastritis/atrophy with $H$. pylori was evident upon histopathological examination.

\section{Immunohistochemistry}

Three adjacent sections $4-\mu \mathrm{m}$ thick were cut onto each of three polylysine-coated glass slides. The sections were deparaffinized, washed in phosphate-buffered saline (PBS), then microwaved in sodium citrate buffer for antigenic retrieval. Immunohistochemical staining for Shh and CDX2 was performed using the Vectastain ABC-AP kit (Vector Laboratories, Burlingame, CA, USA). Endogenous peroxidase activity was quenched by incubation in 3\% hydrogen peroxide in methanol for $30 \mathrm{~min}$. After non-specific binding was blocked, sections were incubated with goat polyclonal alphaShh antibody (1:100; Santa Cruz Biotechnology, Santa Cruz, CA, USA) or CDX2 (1:500; BioGenex, San Ramon, CA, USA) overnight at $4{ }^{\circ} \mathrm{C}$. After washing in $\mathrm{PBS}$, the sections were incubated for 30 min with biotinylated IgG (DAKO, Carpinteria, CA, USA). They were then washed and incubated with an avidin and biotinylated alkaline phosphatases complex for $30 \mathrm{~min}$, washed in PBS, stained in $0.05 \%$ diaminobenzidine hydrochloride solution for $5 \mathrm{~min}$, then counterstained with haematoxylin. After dehydration with xylene, the sections were mounted.

Shh or CDX2 staining was quantified for each subject as the number of stained cells per gland or per 100 cells.

\section{Statistical analyses}

Values are expressed as the mean \pm s.d. or the median with a 25-75\% range, whichever was appropriate depending on whether the data were normally distributed. Mantel-Haenszel chi-square analysis and the unpaired $t$-test were performed to measure differences in demographic and clinical characteristics. Statistical analyses for significant differences of parameters were performed using the non-parametric Mann-Whitney $U$-test between two groups. Among three groups, the Kruskal-Wallis test was used and all pairwise multiple comparisons were performed using the Dunnet method. 
The Pearson chi-square analysis was used to detect a significant difference in the type of IM between the two groups and the Mantel-Haenszel chi-square analysis was used to assess the relationship between gastric cancer and incomplete IM by odds ratio (OR) and 95\% confidence interval (CI). Spearman's correlation coefficient was calculated to examine correlations among histological parameters. Stepwise linear regression analysis was performed between Shh or CDX2 expression and other histological scores. A two-sided $P$-value of less than 0.05 was considered statistically significant. All statistical computations were performed using SPSS (SPSS Inc., Chicago, IL, USA).

\section{RESULTS}

The study groups consisted of 60 patients with EMR for early gastric cancer (cancer group) and an additional 60 in the control group who were matched to the EMR group by gender, age and the presence of $H$. pylori infection. Demographic and clinical characteristics of the study groups are shown in Table 1. Malignant lesions in the corpus were found in 24 patients and 28 patients had lesions in the lower stomach. In the remaining eight patients, malignant lesions were located in two different locations. Atrophy and IM scores for each part and inflammation in the greater curve of the corpus were significantly higher in the cancer group than in the control group (Figure 1).

Incomplete IM was present in 46 patients (76.7\%) in the cancer group and 17 patients (28.3\%) in the control group. Relatively more patients in the gastric cancer group had incomplete IM, with high significance $(P<0.001)$ (Table 2). The sensitivity and specificity of incomplete IM for gastric cancer were $76.7 \%$ and $71.7 \%$, respectively, and gastric cancer was associated

Table 1. Patient demographic and clinical characteristics

\begin{tabular}{lccc}
\hline & $\begin{array}{l}\text { Control } \\
(n=60)\end{array}$ & $\begin{array}{l}\text { Cancer } \\
(n=60)\end{array}$ & $P$-values \\
\hline Age mean (s.d.) & $69(10)$ & $69(8)$ & $0.72^{\mathrm{a}}$ \\
Gender male/female & $46 / 14$ & $46 / 14$ & \\
Helicobacter pylori-positive & $90 \%$ & $90 \%$ & \\
Current smokers & $28.3 \%$ & $38.3 \%$ & $0.47^{\mathrm{b}}$ \\
Regular alcohol intake & $46.7 \%$ & $41.7 \%$ & $0.80^{\mathrm{b}}$
\end{tabular}

$P$-values calculated using: ${ }^{\mathrm{a}}$ unpaired $t$-test, ${ }^{\mathrm{b}}$ Mantel-Haenszel chi-square analysis. with a higher frequency of incomplete IM $(\mathrm{OR}=8.3$; 95\% CI, 3.7-18.9, $P<0.001$ ).

A large number of Shh-positive cells in the fundic glands (Figure 2a) and a few CDX2-positive cells in areas with IM (Figure 2b) were seen in controls without atrophy. Shh-positive cells were dramatically reduced (Figure 2c) and many CDX2-positive cells were seen (Figure 2d) in cancer patients with complete IM. In specimens that contained incomplete IM, Shh expression was nearly absent (Figure 2e) and a large number of CDX2-positive cells were seen (Figure 2f) in the whole specimens, especially in cancer patients. The presence of Shh peptide and CDX2 significantly correlated with the scores of inflammation from the greater curve of the corpus and the scores of atrophy and IM in each part (Table 3). CDX2 expression negatively correlated with Shh expression $(r=-0.73, P<0.001$, Figure 3). In multivariate analysis, Shh expression in the corpus correlated significantly only with the atrophy scores $(P<0.001)$. CDX2 correlated significantly with the IM scores $(P<0.001)$ and also with the Shh scores in the lesser curve of the corpus $(P=0.03)$.

The median of Shh indices in the corpus was significantly lower (18 vs. $34, P<0.001$ in the greater curve of the corpus; 0.4 vs. 9.2, $P=0.002$ in the lesser curve of the corpus) and the median percentage of CDX2-positive cells in the lesser curve of the corpus was significantly higher (80 vs. $10, P<0.001$ ) in the cancer group than in the control group (Figure 4). The Shh indices in the corpus decreased and the CDX2 indices in the respective areas increased in patients without IM, patients with complete IM and patients with incomplete IM, in that order $(P<0.001)$. There was a significant difference between the complete and incomplete IM groups for Shh expression in the corpus and for CDX2 expression in both the antrum and the lesser curve of the corpus (Figure 5).

\section{DISCUSSION}

We previously reported that Shh expression correlated with atrophy and IM score, and that its expression decreased in H. pylori-negative controls, -positive controls and the cancer group, in that order. ${ }^{16}$ In the present study, CDX2 positively correlated with atrophy and IM scores, but negatively correlated with Shh expression. CDX2 expression in the lesser curve of the corpus was significantly higher in the cancer group than in the control group. However, we found no significant difference between Shh and CDX2 expression 
(a)

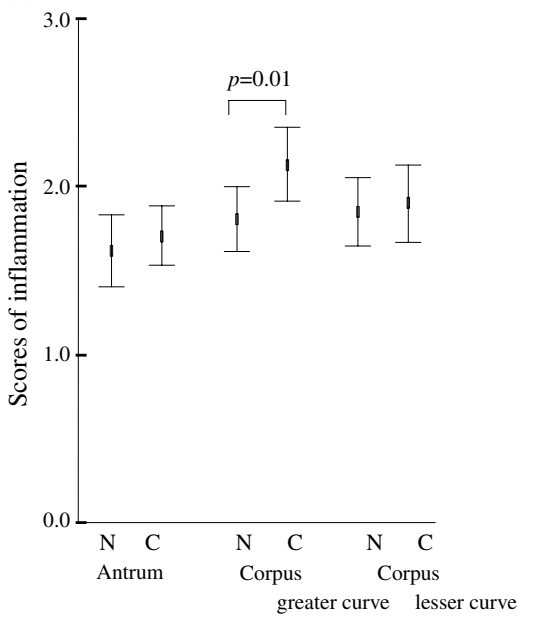

(b)

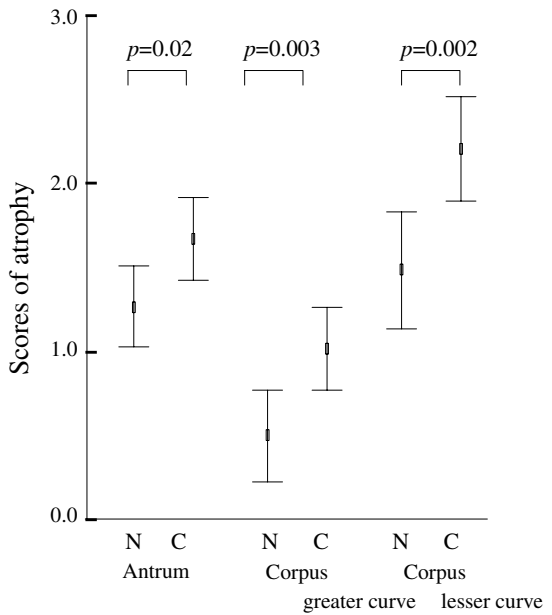

(c)

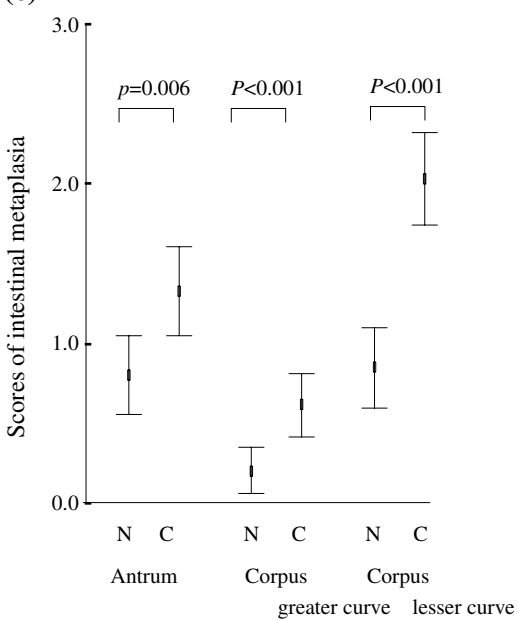

Figure 1. Comparisons of histological scores between the control group (N) and the cancer group (C). Mean scores with 95\% confidence intervals. $P$-values were calculated using the non-parametric Mann-Whitney $U$-test.

Table 2. The prevalence of type of intestinal metaplasia

\begin{tabular}{lcll}
\hline & None & $\begin{array}{l}\text { Complete } \\
\text { intestinal } \\
\text { metaplasia }\end{array}$ & $\begin{array}{l}\text { Incomplete } \\
\text { intestinal } \\
\text { metaplasia }\end{array}$ \\
\hline Control & 16 & 27 & 17 \\
Cancer & 4 & 10 & 46 \\
\hline
\end{tabular}

Pearson $\chi^{2} P<0.001$.

that corresponded to the location of the malignant lesions. Thus, the loss or reduction of Shh expression and aberrant CDX2 expression seem to be essential factors in the induction of carcinogenesis during the early phases of transformation, which suggests in turn that numerous other genetic changes such as p53, k-ras and microsatellite instability, etc. may also be involved. Recently, Mutoh et al. reported that gastric polyps developing from the intestinal metaplastic mucosa of all stomachs in Cdx2-transgenic mice consisted of intestinal-type adenocarcinoma containing p53 and APC gene mutations, ${ }^{29}$ and suggested that aberrant CDX2 expression inducing IM plays a significant role in the genesis and progression of gastric carcinoma. However, there is no direct evidence of loss of Shh expression for carcinogenesis. Ramalho-Santos et al. reported that Shh-null mice exhibit an overgrowth of stomach epithelium that, upon histological examination, appears to be glandular epithelium remi- niscent of an intestinal phenotype. Moreover, the transformation of the stomach epithelium does not depend on alterations in the expression of the $C d x 2$ genes. ${ }^{12}$ Thus, independently of CDX2, Shh seems to be associated with gastric cancer preventing atrophy prior to IM.

The IM phenotype is characterized by the presence of intestinal differentiation markers like apomucin MUC2. ${ }^{30}$ It has been reported that Shh-expressing cells are present adjacent to metaplastic glands containing goblet cells expressing MUC2, and that the expression of Shh and MUC2 is mutually exclusive. ${ }^{15}$ Tsukamoto et al. analysed CDX2 mRNA levels in isolated gastric glands and demonstrated that the expression of CDX2 as well as of MUC2 is progressively upregulated with intestinalization from the gastric type to the gastric/ intestinal-mixed type to the intestinal type. ${ }^{31}$ Thus, Shh appears to be an essential signal of fundic gland differentiation and might prevent the modulation of the differentiated gastric mucosa to an IM phenotype. In contrast, CDX2 seems to be a signal essential for modulation to an IM phenotype and might function by preventing the execution of a fundic gland differentiation pattern. Atrophic change, specifically the loss of parietal cells, leads to the loss of Shh expression, which might in turn lead to aberrant expression of CDX2.

Shh binds to its receptor Patched (Ptc), which reduces the inhibitory effect of Ptc on another transmembrane protein, Smoothened (Smo). Shh signalling is finally carried out by members of the Gli-family of 

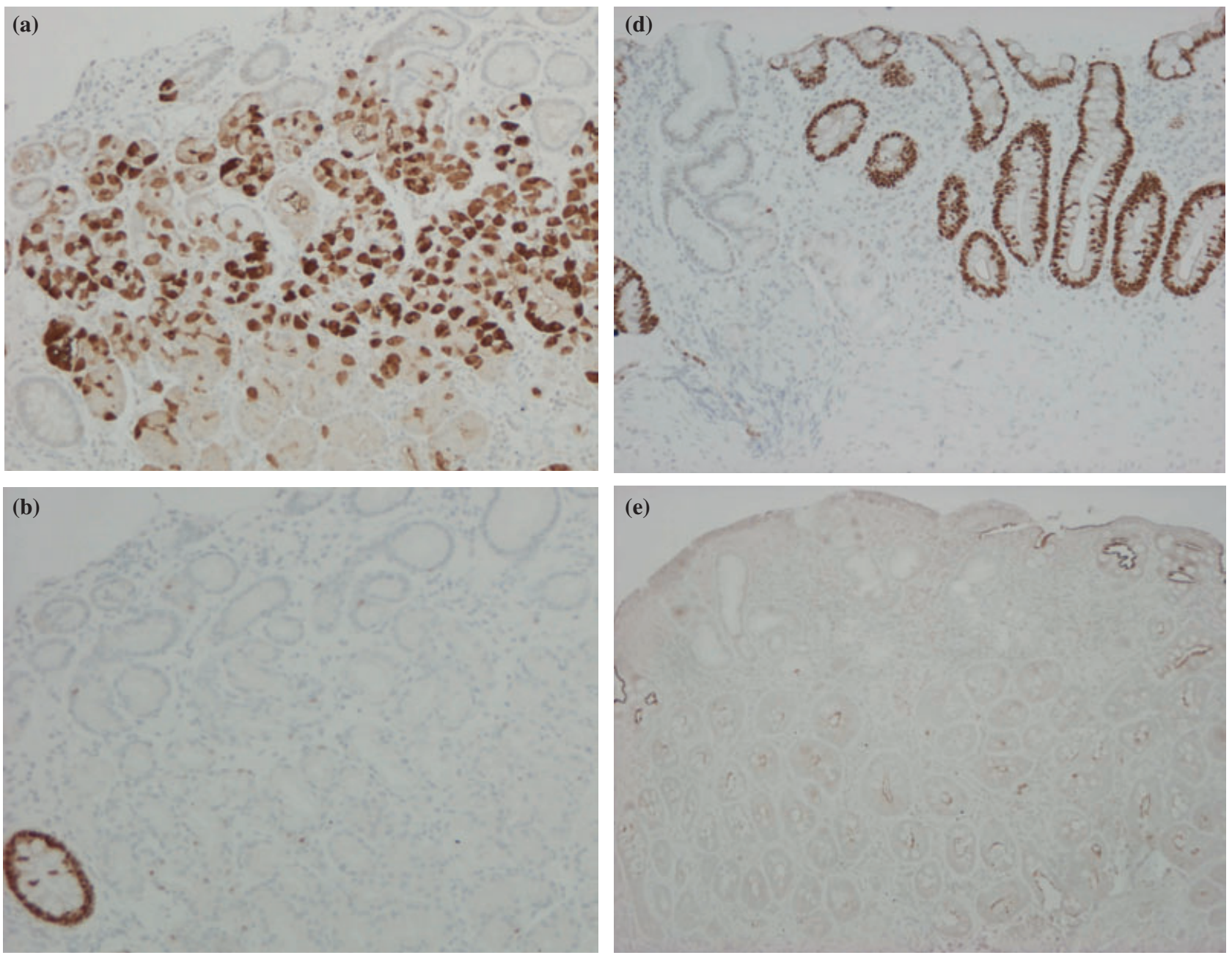

(e)
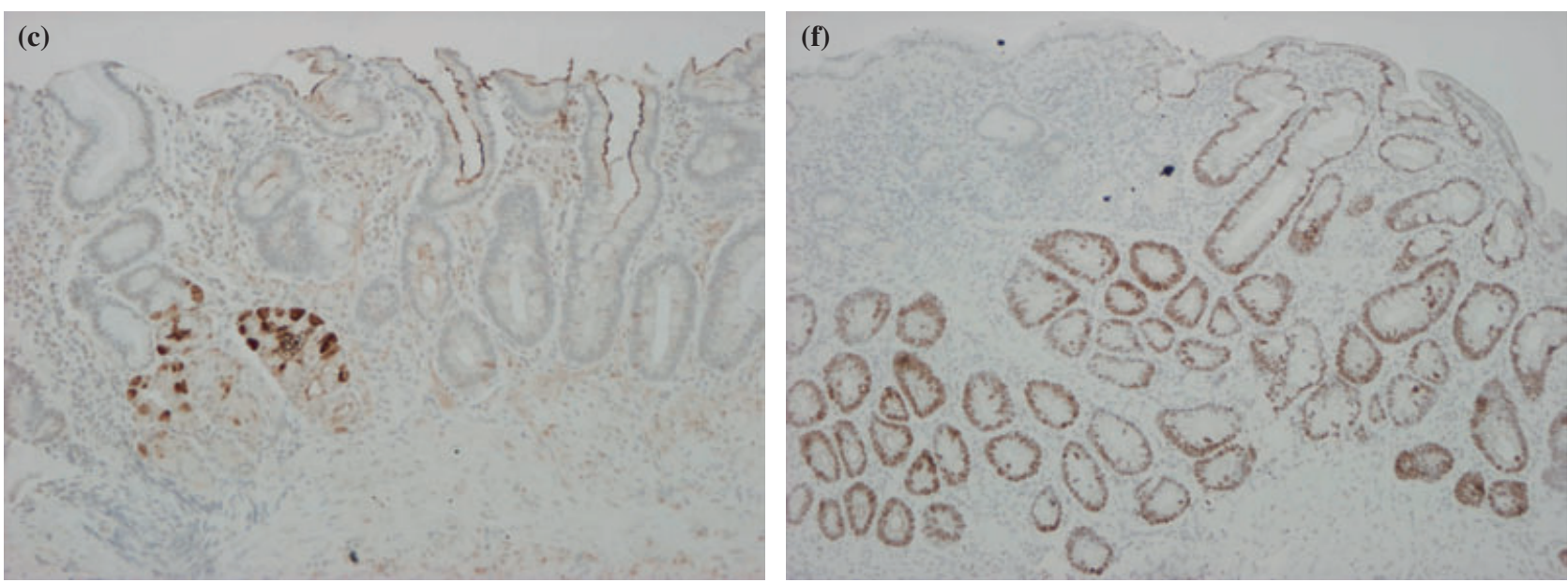

Figure 2. Expression of sonic hedgehog (Shh) and CDX2 in biopsy tissue from the lesser curve of the corpus from cancer and control groups. In specimens from control subjects without atrophy, Shh staining observed in parietal cells (a) and CDX2-positive cells were observed only in areas with intestinal metaplasia (IM) (b). Reduced numbers of Shh-stained cells (c) and many CDX2-positive cells were seen in the cancer patients (d). In specimens that contained incomplete IM, Shh expression was essentially absent (e) and a large number of CDX2-positive cells were detected (f). 
Table 3. Correlation among the histological parameters

\begin{tabular}{|c|c|c|c|c|}
\hline & Inflammation & Atrophy & $\begin{array}{l}\text { Intestinal } \\
\text { metaplasia }\end{array}$ & Shh \\
\hline Shh in the antrum & -0.17 & $-0.46^{* * *}$ & $-0.24^{*}$ & \\
\hline Shh in the corpus: greater curve & $-0.43^{* * *}$ & $-0.79^{* * *}$ & $-0.54^{* * *}$ & \\
\hline Shh in the corpus: lesser curve & $-0.24^{*}$ & $-0.73^{* * *}$ & $-0.70^{* * *}$ & \\
\hline $\mathrm{CDX} 2$ in the antrum & -0.15 & $0.55^{* * *}$ & $0.75^{* * *}$ & $-0.39^{* * *}$ \\
\hline CDX2 in the corpus: greater curve & $0.29^{* *}$ & $0.56^{* * *}$ & $0.66^{* * *}$ & $-0.52^{* * *}$ \\
\hline CDX2 in the corpus: lesser curve & 0.05 & $0.67^{* * *}$ & $0.83^{* * *}$ & $-0.73^{* * *}$ \\
\hline
\end{tabular}

Shh, sonic hedgehog; ${ }^{*} P<0.05,{ }^{* *} P<0.01$, ${ }^{* * *} P<0.001$.

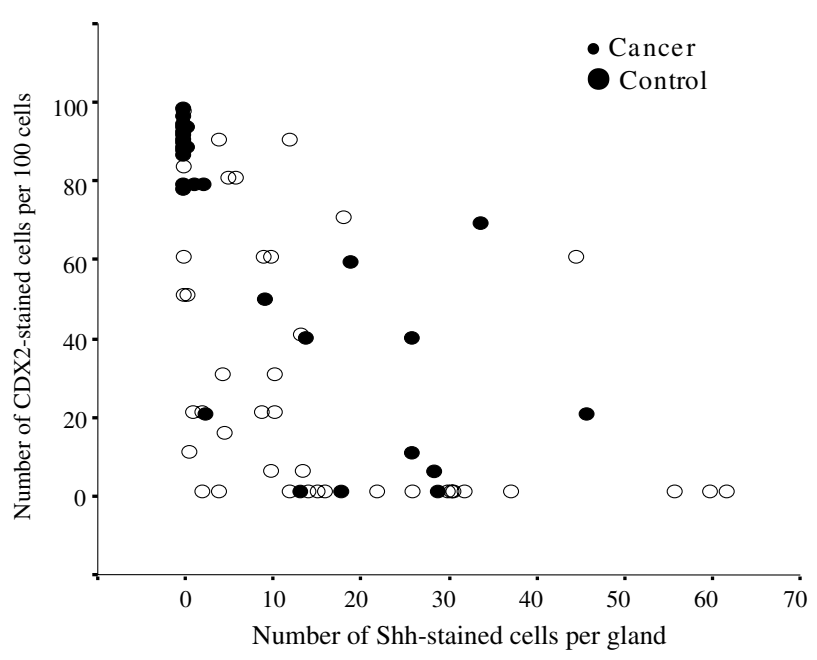

Figure 3. Correlation between the sonic hedgehog (Shh) and CDX2 staining indices in the lesser curve of the corpus in controls $(\bigcirc)$ and patients with gastric cancer $(O)$.

transcription factors, which co-ordinately pattern the dorsal-ventral axis of the spinal cord. ${ }^{32-34}$ Runx3, a runt domain transcription factor, is a major growth regulator of gastric epithelial cells and some gastric epithelial cells in the Runx $3^{-1-}$ mouse differentiate into intestinal-type cells expressing CDX2. ${ }^{35}$ Sucraseisomaltase, glucagon, carbonic anhydrase I, lactase, MUC2, etc. have been suggested as candidates for CDX2-regulated target genes. Moreover, CDX2 appears to directly regulate the LI-cadherin (cadherin 17) gene, which is an intestine-specific cell adhesion molecule, and hephaestin, which plays a critical role in the transport of iron into the intestinal epithelium. ${ }^{36}$ In this way, CDX2 and Shh seem to be involved in intestinal transformation interdependently through different signal cascades.
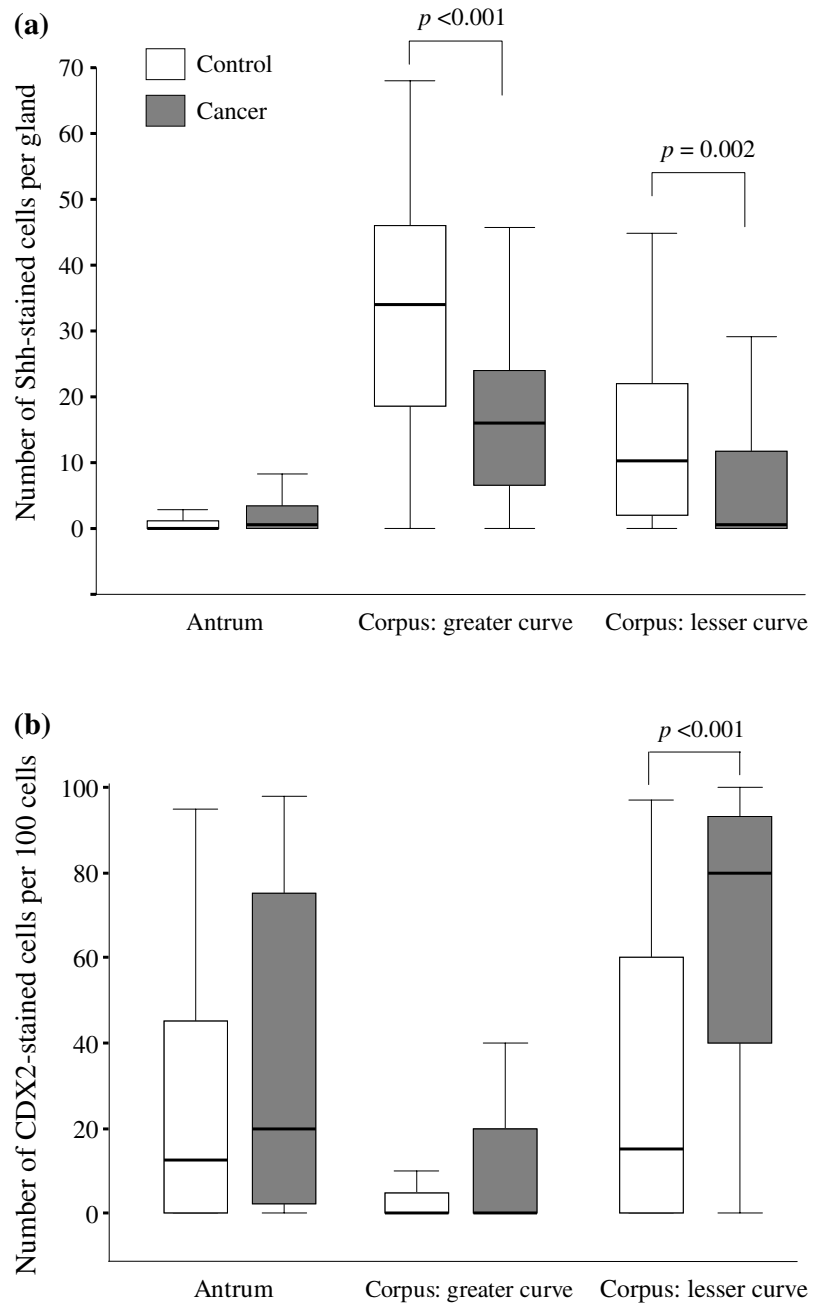

Figure 4. Comparison of sonic hedgehog (Shh) (a) and CDX2 (b) expression in control and cancer groups. Horizontal bar, median; box, 25th-75th interquartile range; vertical lines, range of values. $P$-values were calculated using the non-parametric Mann-Whitney $U$-test and the Dunnet method. 
(a)
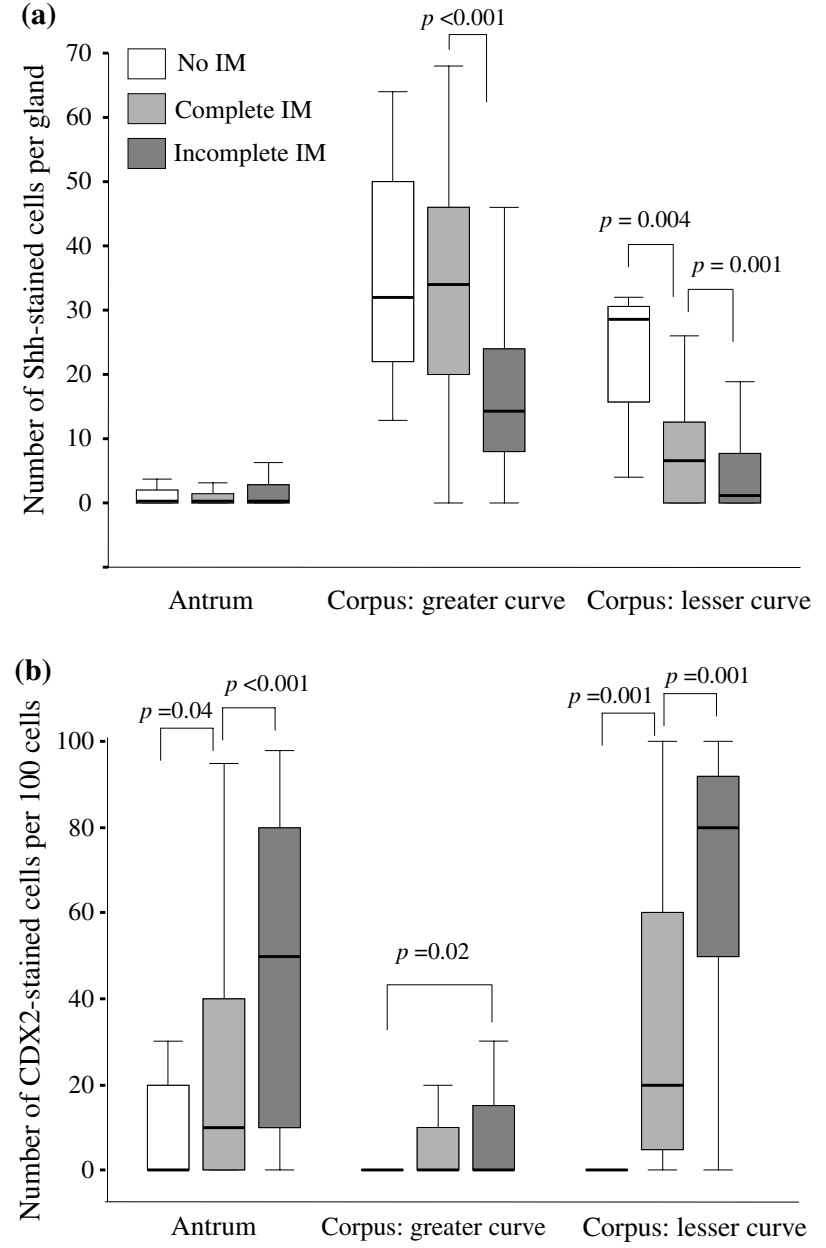

Figure 5. Comparison of sonic hedgehog (Shh) (a) and CDX2 (b) expression in patients without intestinal metaplasia (IM), complete IM and incomplete IM. Horizontal bar, median; box, 25th-75th interquartile range; vertical lines, range of values. $P$-values were calculated using the Dunnet method.

Gastric juice $\mathrm{pH}$ is likely a useful marker of highrisk gastric cancer. ${ }^{37,38}$ Dimmler et al. reported that transcription of Shh in a gastric cancer cell line was significantly increased in culture conditions with low $\mathrm{pH}$ and suggested that an increase in gastric $\mathrm{pH}$ may play a role in the development of gastric mucosa atrophy via reduction of Shh transcription. ${ }^{39}$ In contrast, in the intestinal cell line Caco2, CDX2 expression is downregulated under acidic conditions. ${ }^{40}$ CDX2 expression in intestinal cells is lost in duodenal gastric metaplasia, which is closely associated with gastric hypersecretion and increased acid load in the duodenum. ${ }^{40}$ The acid-induced loss of CDX2 expression may be a reflection of the pathological mechanism of IM in the stomach. Thus, gastric CDX2 expression and intestinal trans-differentiation in the gastric mucosa can be suppressed by the normal acidic milieu of the corpus mucosa. Hypoacidity due to reduced acid secretion caused by gastric atrophy might allow the upregulation of CDX2, resulting in IM.

The results of this study show that a small number of CDX2-positive cells occur in the antrum even without the presence of IM, although no expression was seen in the corpus without IM. In previous reports, CDX2 expression in antrum infected with $H$. pylori without obvious IM has been described and a small amount of CDX2 expression in isolated gastric-type gland from the antrum has also been shown. ${ }^{31,41} \mathrm{~A}$ small amount of antrum CDX2 expression without IM that is unrelated to changes in Shh expression might trigger the initiation and development of IM.

In addition, we found a significant difference in CDX2 and Shh expression according to the type of IM involved. It has been reported that the majority of intestinal-type goblet cells in Foxa 3/Cdx2 transgenic mice produced sulphated mucin, which indicates type III IM, although intestinal genes such as alkaline phosphatase, villin, Muc2 and trefoil family factor 3 were also activated. ${ }^{22}$ However, the molecular pathogenesis underlying the morphological alterations caused by complete and incomplete IM, and type III IM remain largely unknown. It is also unclear whether CDX2 and Shh are specifically involved with these intestinal transformations.

In conclusion, our study suggests that the loss of Shh and aberrant expression of CDX2 in H. pyloriassociated atrophic gastritis are early changes that occur in the mucosa prior to cellular transformation and correlate with the type of IM. Shh and CDX2 may play an important and interdependent role in sustaining gastric epithelial differentiation and might be subsequently involved in carcinogenesis at an early stage.

\section{ACKNOWLEDGEMENT}

This study was supported in part by US Public Health Service Grant R01 DK61410 to JLM. 


\section{REFERENCES}

1. Correa P. Chronic gastritis as a cancer precursor. Scand J Gastroenterol Suppl 1984; 104: 131-6.

2. Filipe MI, Potet F, Bogomoletz WV, et al. Incomplete sulphomucin-secreting intestinal metaplasia for gastric cancer. Preliminary data from a prospective study from three centres. Gut 1985; 26: 1319-26.

3. El-Zimaity HM, Ota H, Graham DY, Akamatsu T, Katsuyama T. Patterns of gastric atrophy in intestinal type gastric carcinoma. Cancer 2002; 94: 1428-36.

4. Matsuzaki H, Shimada S, Uno K, Tsuruta J, Ogawa M. Novel subtyping of intestinal metaplasia in the human stomach: brain-type glycogen phosphorylase expression in the proliferative zone and its relationship with carcinogenesis. Am J Clin Pathol 1998; 109: 181-9.

5. Matsukura N, Suzuki K, Kawachi T, et al. Distribution of marker enzymes and mucin in intestinal metaplasia in human stomach and relation to complete and incomplete types of intestinal metaplasia to minute gastric carcinomas. J Natl Cancer Inst 1980; 65: 23140.

6. Iida F, Kusama J. Gastric carcinoma and intestinal metaplasia. Significance of types of intestinal metaplasia upon development of gastric carcinoma. Cancer 1982; 50: 2854-8.

7. Meining A, Morgner A, Miehlke S, Bayerdorffer E, Stolte M. Atrophy-metaplasia-dysplasia-carcinoma sequence in the stomach: a reality or merely an hypothesis? Best Pract Res Clin Gastroenterol 2001; 15: 983-98.

8. Nusslein-Volhard C, Wieschaus E. Mutations affecting segment number and polarity in Drosophila. Nature 1980; 287: 795-801.

9. Hammerschmidt M, Brook A, McMahon AP. The world according to hedgehog. Trends Genet 1997; 13: 14-21.

10. Bitgood MJ, McMahon AP. Hedgehog and Bmp genes are coexpressed at many diverse sites of cell-cell interaction in the mouse embryo. Dev Biol 1995; 172: 126-38.

11. Echelard Y, Epstein DJ, St-Jacques B, et al. Sonic hedgehog, a member of a family of putative signaling molecules, is implicated in the regulation of CNS polarity. Cell 1993; 75: 1417-30.
12. Ramalho-Santos M, Melton DA, McMahon AP. Hedgehog signals regulate multiple aspects of gastrointestinal development. Development 2000; 127: 2763-72.

13. Litingtung $\mathrm{Y}$, Lei L, Westphal H, Chiang C. Sonic hedgehog is essential to foregut development. Nat Genet 1998; 20: 58-61.

14. van den Brink GR, Hardwick JC, Tytgat $\mathrm{GN}$, et al. Sonic hedgehog regulates gastric gland morphogenesis in man and mouse. Gastroenterology 2001; 121 : 317-28.

15. van den Brink GR, Hardwick JC, Nielsen $\mathrm{C}$, et al. Sonic hedgehog expression correlates with fundic gland differentiation in the adult gastrointestinal tract. Gut 2002; 51: 628-33.

16. Shiotani A, Iishi H, Uedo N, et al. Evidence that loss of sonic hedgehog is an indicator of Helicobacter pylori-induced atrophic gastritis progressing to gastric cancer. Am J Gastroenterol 2005; 100 : 581-7.

17. Silberg DG, Swain GP, Suh ER, Traber PG. Cdx1 and cdx2 expression during intestinal development. Gastroenterology 2000; 119: 961-71.

18. Macdonald PM, Struhl G. A molecular gradient in early Drosophila embryos and its role in specifying the body pattern. Nature 1986; 324: 537-45.

19. Moreno E, Morata G. Caudal is the Hox gene that specifies the most posterior Drosophile segment. Nature 1999; 400: 873-7.

20. Beck F, Chawengsaksophak K, Waring P, Playford RJ, Furness JB. Reprogramming of intestinal differentiation and intercalary regeneration in $\mathrm{Cdx} 2$ mutant mice. Proc Natl Acad Sci U S A 1999; 96: 7318-23.

21. Phillips RW, Frierson HF Jr, Moskaluk CA. $\mathrm{Cdx} 2$ as a marker of epithelial intestinal differentiation in the esophagus. Am J Surg Pathol 2003; 27: 14427.

22. Silberg DG, Sullivan J, Kang E, et al. $\mathrm{Cdx} 2$ ectopic expression induces gastric intestinal metaplasia in transgenic mice. Gastroenterology 2002; 122: 689-96.

23. Matsumoto K, Mizoshita T, Tsukamoto $\mathrm{T}$, et al. $\mathrm{Cdx} 2$ expression in pancreatic tumors: Relationship with prognosis of invasive ductal carcinomas. Oncol Rep 2004; 12: 1239-43.
24. Piscitelli D, Ingravallo G, Resta L, Fiore MG, Maiorano E. Oncocytic adenocarcinoma of the rectum with diffuse intraluminal microcalcifications: the first reported case. Virchows Arch 2003; 443: 579-82.

25. Kaimaktchiev V, Terracciano L, Tornillo $\mathrm{L}$, et al. The homeobox intestinal differentiation factor CDX2 is selectively expressed in gastrointestinal adenocarcinomas. Mod Pathol 2004; 17: 1392-9.

26. Mizoshita T, Tsukamoto T, Nakanishi H, et al. Expression of $\mathrm{Cdx} 2$ and the phenotype of advanced gastric cancers: relationship with prognosis. $J$ Cancer Res Clin Oncol 2003; 129: 727-34.

27. Seno H, Oshima M, Taniguchi MA, et al. CDX2 expression in the stomach with intestinal metaplasia and intestinal-type cancer: prognostic implications. Int $J$ Oncol 2002; 21: 769-74.

28. Dixon MF, Genta RM, Yardley JH, Correa P. Classification and grading of gastritis. The updated Sydney System. International Workshop on the Histopathology of Gastritis, Houston 1994. Am J Surg Pathol 1996; 20: 1161-81.

29. Mutoh H, Sakurai S, Satoh K, et al. Development of gastric carcinoma from intestinal metaplasia in Cdx2-transgenic mice. Cancer Res 2004; 64: 7740-7.

30. Seregni E, Botti C, Massaron S, et al. Structure, function and gene expression of epithelial mucins. Tumori 1997; 83: 625-32.

31. Tsukamoto $\mathrm{T}$, Inada $\mathrm{K}$, Tanaka $\mathrm{H}$, et al. Down-regulation of a gastric transcription factor, Sox2, and ectopic expression of intestinal homeobox genes, $\mathrm{Cdx} 1$ and $\mathrm{Cdx} 2$ : inverse correlation during progression from gastric/intestinalmixed to complete intestinal metaplasia. $J$ Cancer Res Clin Oncol 2004; 130: 135-45.

32. Oldak M, Grzela T, Lazarczyk M, Malejczyk J, Skopinski P. Clinical aspects of disrupted Hedgehog signaling (review). Int J Mol Med 2001; 8: 445-52.

33. Faller G, Kirchner T. Immunological and morphogenic basis of gastric mucosa atrophy and metaplasia. Virchows Arch 2005; 446: 1-9.

34. Jacob J, Briscoe J. Gli proteins and the control of spinal-cord patterning. EMBO Rep 2003; 4: 761-5.

35. Fukamachi H, Ito K, Ito Y. Runx3-/gastric epithelial cells differentiate into 
intestinal type cells. Biochem Biophys Res Commun 2004; 321: 58-64.

36. Hinoi T, Lucas PC, Kuick R, Hanash S, Cho KR, Fearon ER. CDX2 regulates liver intestine-cadherin expression in normal and malignant colon epithelium and intestinal metaplasia. Gastroenterology 2002; 123: 1565-77.

37. Shiotani A, Iishi H, Kumamoto M, Nakae Y. Helicobacter pylori infection and increased nitrite synthesis in the stomach. Inflammation and atrophy connections. Dig Liver Dis 2004; 36: 327-32.

38. Shiotani A, Iishi H, Uedo N, et al. Hypoacidity combined with high gastric juice nitrite induced by Helicobacter pylori infection is associated with gastric cancer. Aliment Pharmacol Ther 2004; 20 (Suppl 1): 48-53.

39. Dimmler A, Brabletz T, Hlubek F, et al. Transcription of sonic hedgehog, a potential factor for gastric morphogenesis and gastric mucosa maintenance, is up-regulated in acidic conditions. Lab Invest 2003; 83: 1829-37.

40. Faller G, Dimmler A, Rau T, et al. Evidence for acid-induced loss of $\mathrm{Cdx} 2$ expression in duodenal gastric metaplasia. J Pathol 2004; 203: 904-8.

41. Satoh K, Mutoh H, Eda A, et al. Aberrant expression of $\mathrm{CDX} 2$ in the gastric mucosa with and without intestinal metaplasia: effect of eradication of Helicobacter pylori. Helicobacter 2002; 7: 192-8. 